\title{
IMPACT OF MOLINATE EXPOSURE ON MALE COURTSHIP BEHAVIOR AND ACETYLCHOLINESTERASE ACTIVITY IN ZEBRAFISH, DANIO RERIO
}

\author{
SHANNON L. SULLIVAN, STEPHEN J. SALEK, and SHIRLEY L. CHAO \\ Department of Biological Sciences, Fayetteville State University, 1200 Murchison Road, Fayetteville, NC 28301 \\ Email:schao@uncfsu.edu
}

\begin{abstract}
Molinate, a thiocarbamate herbicide, is used to control broad-leaf and grassy weeds. Studies have shown that molinate alters a range of animal behaviors to produce the following symptoms following exposure: lethargy, erratic swimming, and tremors. Fish, in particular, showed variability in sensitivity to molinate. Possible mechanism of action in such observed behavior is alteration in the cholinergic nervous system responsible for messenger transmission in the central nervous system and peripheral nervous system. The current study examined the possible disruption of spawning behavior in zebrafish (Danio rerio) following molinate exposure. Findings indicate that while various forms of spawning behavior were not altered significantly in fish exposed to molinate, a significant difference was observed in the total number of eggs produced; control fish produced approximately twice as many eggs compared to molinate-treated fish. Furthermore, significantly higher levels of acetylcholinesterase activity were observed in male fish, indicating a compensatory mechanism following toxic insult. In conclusion, while molinate does not appear to impact male courtship behavior in zebrafish, the pesticide does appear to alter acetylcholinesterase activity in males, suggesting disruption of the nervous system in males.
\end{abstract}

Key Words: zebrafish; courtship behavior; molinate; acetylcholinesterase.

\section{INTRODUCTION}

Many studies have examined the effects of toxicants on reproduction in various vertebrates as cited in the review by Quignot et al. (2012) and Guillette et al. (1996). One such toxicant is molinate, $\left(\mathrm{C}_{9} \mathrm{H}_{17} \mathrm{NOS}\right), \mathrm{S}-$ ethyl hexahydro-1H-azepine-1-carbothioate. Molinate is a thiocarbamate herbicide used to control germinating broad-leaf and grassy weeds in rice paddies and in other crops. While the primary mode of action of molinate in plants appears to be the disruption of photosynthesis, studies have shown alternative mechanisms of action in nontarget species. Molinate exposure caused significant changes in behavior in animal models studied. These changes ranged from lethargy and reduced opercular movements to restlessness, erratic swimming, and tremors (Sancho et al. 2000; Fernandez-Vega et al. 1999; Sanchez et al. 2004; Julli and Krassoi 1995; Galhano et al. 2009). In fish, toxicity varied greatly depending on the species of fish examined with $\mathrm{LC}_{50}$ ranging from $0.21 \mathrm{mg} / \mathrm{L}$ in rainbow trout, Oncorhynchus mykiss (Johnson and Finley 1980), to $30 \mathrm{mg} / \mathrm{L}$ in goldfish, Carassius auratus (USNLM 1995).

Molinate is structurally similar to carbamate pesticides and can inhibit acetylcholinesterase (AChE) activity at synapses and at neuromuscular junctions in several species (Hodgson and Levi 1987; Frasco et al. 2006). Acetylcholinesterase is routinely measured as a biomarker of exposure to carbamate insecticides like molinate (Grue et al. 1997). Accumulation of acetylcholine at central cholinergic synapses and at vertebrate neuromuscular junction can occur with low concentrations of these compounds (Gupta 1994). Locomotion and equilibrium can be affected because of the accumulation of acetylcholine in exposed fish, (Little et al. 1990; Richmonds and Dutta 1992; Saglio et al. 1996). Studies in fish have shown the inhibition of acetylcholinesterase activity by high concentrations of carbofuran, another carbamate (Jash and Bhattacharya 1983; Trotter et al. 1991).

Many studies have examined reproductive behavior in various fish; however, the details of zebrafish (Danio rerio) spawning behavior remain largely unexplored. Existing studies have shown the following: zebrafish are sexually stimulated by pheromones of conspecifics in specific concentrations (Bloom and Perlmutter 1977); they breed in the early morning hours; and they prefer to spawn near artificial substrates (Westerfield 1989). Guthrie and Muntz (1993) gave a general overview of zebrafish behavior, and found that courtship and spawning involve abrupt turns and elliptical swimming patterns around the female. A partial ethogram of male and female spawning behaviors has been published (Darrow and Harris 2004). The developments of courtship behavior and density effects on oviposition have also been examined (Darrow and Harris 2004; Spence and Smith 2005). The predominant courtship behaviors 
we observed include: encircle, tail-nose, follow and possible spawn. Tail-nose and encircle were described and quantified by Darrow and Harris (2004). However, previous studies on zebrafish have not described the behaviors of follow and possible spawn. These specific behaviors have been observed in other fish species.

The Mozambique tilapia (Oreochromis mossambichus) displays the behavior of follow when courting males are followed to the nest by females (Oliveira et al. 2005). The Atlantic salmon (Salmo salar), white perch (Morone americana), and striped bass ( $M$. saxatilis) display a behavior similar to tail nose (Salek et al. 2001a,b). The males touch the females with their snout on either the abdomen or the head (De Gaudemar and Beall 1999). This behavior is also exhibited by the ThreeSpined Sticklebacks (Gasterosteus aculeatus) as the males charge and butt the females with their snouts (Rowland et al. 2002).

The Atlantic salmon males crossover and swim around the female as they display a behavior much like Encircle (De Gaudemar and Beall 1999). The ThreeSpined Stickleback males sometimes circle around the females (Rowland et al. 2002) as well as the Mozambique tilapia, The courtship male of the Mozambique tilapia assume a pivot position in the nest while another male circles them (Oliveira et al. 2005).

The male courtship behaviors of encircle, nose to tail and follow are displayed most abundantly based on previous studies (Darrow and Harris 2004). Possible spawn occurs when the male approaches the female from the side or behind, contacts the female and both fish swim quickly in a circle around each other. The female swims away and the male often flips his tail at the end of the contact. In order to understand the impact that molinate has on the reproductive behavior of fish, normal spawning behavior was examined as well as spawning behavior after toxic insult with molinate. The zebrafish is a useful vertebrate model for testing human diseases and comparable genes. Other fish produced varied results; therefore zebrafish were chosen as the animal model for the current study. We tested our hypothesis that molinate would disrupt spawning behavior by disrupting the nervous system of male zebrafish. As a result, we expected male zebrafish to alter their spawning behavior following exposure to molinate.

\section{MATERIALS AND METHODS}

\section{Husbandry}

For each experiment, 200 male and 200 female adult zebrafish, were obtained from Carolina Biological (Burlington, NC) and acclimated to laboratory conditions in holding tanks for at least one week prior to use. Fish were housed in 55 gal community tanks supplied with stock tank water (160 gal tap water, $25 \mathrm{~mL}$ Ultimate Water Conditioner (AquaScience), $15 \mathrm{~mL}$ Neutral Regulator (Seachem Madison GA), and 150 $\mathrm{mL}$ Coralife Salt (Energy Savers Unlimited Carson CA.) $24-27^{\circ} \mathrm{C}, \mathrm{pH}$ of $6.8-7$ ). A photoperiod of $14 \mathrm{hrs}$ light and $10 \mathrm{hrs}$ darkness was used to stimulate optimal breeding. Fish were fed a diet consisting of live Brine Shrimp, frozen Brine Shrimp, frozen Tubifex Worms, OSI Brine Shrimp Flake food, and Topfin Tropical flakes. Food was obtained from Carolina Biological (Burlington, NC). A 25\% water exchange by vacuuming gravel was performed on all holding tanks once monthly. Algae were minimized using an algae scraper as needed.

\section{Test Chemicals}

Technical grade molinate, S-ethyl hexahydro-1Hazepine-1-carbothioate (98.5\% purity) was purchased from ChemService (West Chester, PA). Stock solutions of molinate were prepared by dissolving in distilled water. Control animals were treated with an equal volume of distilled water. Final concentration exposures were determined using dilutions ranging from $0.1 \mathrm{mg} / \mathrm{L}$ to $15 \mathrm{mg} / \mathrm{L}$ in pilot studies (data not shown); the final concentration of $15 \mathrm{mg} / \mathrm{L}$ was used as optimal for observing behavioral parameters.

\section{Exposure and Behavior Assay}

One female and one male were removed from community tanks into a 80L benchtop system (AquaticHabitats, Apopka Fl) equipped with egg collectors. Each pair was placed in a separate tank of the following dimensions: $23 \times 19 \times 17 \mathrm{~cm}$ and $7.43 \mathrm{~L}$. Male and female fish were matched based on size and weight to reduce variability in eggs produced. Males and females acclimated overnight and the egg collectors from each tank were checked for the presence of eggs. Tanks that produced pairs of animals that produced eggs represented a proven spawning pair. The males from this tank were removed, weighed, and fins clipped for identification. Next, they were placed into an $80 \mathrm{~mL}$ plastic beaker containing $15 \mathrm{mg} / \mathrm{L}$ molinate treated system water (Treated group), or system water containing no molinate (Control group). Males remained in these beakers for a two-hour time period; the maximum time observed that did not lead to mortality. Subsequently, each male was placed into the experiment tank (described below) with the female of which he was previously housed. The female from this tank was weighed and placed into the experiment tank $15 \mathrm{~min}$ prior to adding the treated males. The fish were then left undisturbed to acclimate. Each spawning pair was videotaped for two hours beginning $5 \mathrm{~min}$ prior to the lights on in order to document courtship and spawning 
behavior. All together, males were exposed to females for a period of at least $14 \mathrm{hrs}$.

Males were removed from the experiment tanks and their heads were removed for acetylcholinesterase testing. The bodies were then dissected to confirm sex. The male heads were stored at $-80^{\circ} \mathrm{C}$ until acetylcholinesterase assays were conducted. The females were discarded.

\section{Behavior Recordings}

Spawning behavior following molinate exposures was videotaped (Panasonic AG 187 camera) from the time the overhead lights turned on 8:45 AM (simulated day break) until 10:45 AM. Videotapes were labeled and converted to DVD.

\section{Experimental Tanks}

Fish behavior experiments were performed in $9.5 \mathrm{~L}$ glass aquariums. The back and sides of the tank were covered with white paper to aid in visualization on video and to prevent fish from observing other fish in nearby experiment tanks. The tank bottom was covered with a grate made of PVC pipe formed into a square and covered with 1 layer of $0.635 \mathrm{~cm}$ diamond plastic mesh screening and 1 layer of $0.317 \mathrm{~cm}$ square plastic mesh screening. Screening was connected to pipe by quick ties. The grate was then covered with a single layer of blue marbles. The tanks were aerated by air stone on low flow. Water temperature was maintained at $24-27^{\circ} \mathrm{C}$ by control of room temperature. Tanks, marbles, and grates were thoroughly cleaned using bleach before reuse; once thoroughly cleaned, tanks were refilled with clean tap water, marbles, and grates.

\section{Egg Collection}

Eggs were collected from each experimental tank after videotaping by siphoning the bottom of the tank under the grate and between the marbles. Eggs were placed into a Petri dish and placed under a dissecting microscope for examination. The total eggs were counted and separated into fertile and non-fertile groups. The fertile eggs were separated into groups of 30 or less and placed into $250 \mathrm{~mL}$ beakers with $150 \mathrm{~mL}$ of water from stock tanks. The beakers were then placed into a $30^{\circ} \mathrm{C}$ Fisher Scientific Isotemp 220 water bath. After 72 hrs, egg fecundity was determined by counting hatched fry and dividing by the number of fertile eggs collected.

\section{Behavior Scoring and Analysis}

Preliminary studies determined that the highest occurrence of spawning behavior occurred just after lights on (at 8:45 AM); therefore, the first 10 min of each trial were analyzed. Behaviors of encircle, tail to nose,
Table 1. Partial ethogram of male zebrafish courtship and spawning behaviors.

\begin{tabular}{|c|c|}
\hline Behavior & Description \\
\hline Encircle & Male circling around or in front of female. \\
\hline Tail-Nose & $\begin{array}{l}\text { Male touching the female's side or tail with nose } \\
\text { or head. }\end{array}$ \\
\hline Follow & $\begin{array}{l}\text { Male swims behind female changing direction } \\
\text { when she does. }\end{array}$ \\
\hline Possible Spawn & $\begin{array}{l}\text { Male approaches female from side or behind, } \\
\text { contacts the female and both swim quickly in } \\
\text { a circle around each other. Female swims away } \\
\text { and male often flips tail at end of contact. }\end{array}$ \\
\hline
\end{tabular}

follow, and possible spawn were quantified by using the Behavior Tracker program (http://www.behaviortracker.com). The following table (Table 1) demonstrates a partial ethogram of male zebrafish courtship and spawning behavior. Encircle occurs when males circle around or in front of females. Tail-Nose occurs when males touch the female's side or tail with their head or nose. Follow occurs when males swim behind females and change direction when the female changes direction. Possible spawn occurs when the male approaches the female from the side or behind, contacts the female and both fish swim quickly in a circle around each other. The female swims away and the male often flips his tail at the end of the contact. Behaviors were quantified by continuous focal point sampling of male zebrafish (Martin and Bateson 1993). The measurements were prepared for statistical analysis.

\section{Protein Assay}

Frozen heads of male zebrafish were weighed, thawed, and homogenized in buffer composed of: $37 \mathrm{mM} \mathrm{NaCl}$, $19 \mathrm{mM}$ Tris $\mathrm{HCl}$ at $\mathrm{pH} 8,7.4 \mathrm{mM} \mathrm{MgCl}_{2}$. Tissues were homogenized using a polytron (Powergen, Fisher Scientific, Hanover Park, IL) for approximately $45 \mathrm{sec}$. Tissues remained on ice during homogenization. The homogenate was then centrifuged for $5 \mathrm{~min}$ at $12,000 \mathrm{~g}$ and supernatant was removed for protein. Total protein was determined by the Coomassie blue method using Bradford dye (Sigma Chemical Co, St. Louis, MO, U.S.A.) and measuring absorbance of samples at 595 nm. Bovine Serum Albumin or BSA (Sigma Chemical Co, St. Louis, MO, U.S.A.) was used as the standard, diluting a stock of $1 \mathrm{mg} / \mathrm{mL}$ BSA solution in a $3.1 \mathrm{~mL}$ assay volume. Approximately $20 \mu \mathrm{l}$ of sample supernatant was measured using the Bradford method (Bradford 1976). The amount of absorbance was proportional to the amount of protein present.

\section{Acetylcholinesterase Assays}

Acetylcholinesterase activity was measured by modifying the method described by Ellman et al. (1961). 
Reproductive behavior was observed and recorded following exposure to chemicals for 2 hrs. Male zebrafish were decapitated $19 \mathrm{hrs}$ following exposure, after behavior was recorded. Heads were then homogenized as described above for measuring protein. Supernatants of homogenized samples were then measured for acetylcholinesterase activity. The reaction was followed by using a spectrophotometer to measure absorbance at $412 \mathrm{~nm}$ in which 2-nitro-5-thiobenzoate anion formed from the reaction has maximal absorbance. The activities of endogenous sulfhydryls (the blank samples) and spontaneous hydrolysis of acetylthiocholine substrate (blank substrate) reacting with the dye were subtracted from the experimental samples to get true acetylcholinesterase measurements.

Acetylcholinesterase activity was measured from the supernatant based on the Ellman method, using acetylthiocholine iodide as the substrate in a $2 \mathrm{~mL}$ reaction medium consisting of: $0.25 \mathrm{mM} \mathrm{5,} \mathrm{5-dithio-}$ bis (2-nitrobenzoic acid) or DTNB, 0.1 M phosphate buffer, $\mathrm{pH} 7.5$, and $0.001 \mathrm{M}$ acetylthiocholine iodide. Absorbance was read at $412 \mathrm{~nm}$ for the following time points: 1, 2, 5, 10, and 15 min. Enzyme activities were standardized by total protein in the supernatant, as measured by the Bradford method described earlier. The acetylcholinesterase activity was replicated and repeated at least two times for each treatment.

\section{STATISTICAL ANALYSIS}

Male zebrafish courtship and spawning behaviors were quantified by counting the number of occurrences of four specific behaviors (Encircle, Tail-Nose, Follow, and Possible Spawn). Occurrences were recorded for a period of ten minutes following the time that the overhead lights were turned on (simulated daybreak).

The results are presented as the mean of at least 3 separate experiments of at least 3 replicates for each experiment \pm standard error (SE). The main effects examined were reaction time course and treatment in an overall ANOVA (SigmaPlot, San Jose, CA). Analysis of the egg production data was conducted using the Kruskal-Wallis One Way ANOVA on Ranks. All Pairwise multiple comparison procedures were conducted using the Tukey Test with significance level of 0.05 (SigmaPlot, San Jose, CA). The main effects examined for the acetylcholinesterase activity data were reaction time course and treatment in a One Way Repeated Measures ANOVA (SigmaPlot, San Jose, CA). All pairwise multiple comparison procedures were performed using the Holm-Sidak method with overall significance level of 0.05 (SigmaPlot, San Jose, CA).

\section{RESULTS}

Spawning Behavior

Encircle was defined as the male circling around or in front of the female. In control males the mean was 25.90 (3.2) (mean $\pm \mathrm{SE}$ ) occurrences $/ 10 \mathrm{~min}$. In males exposed to molinate the mean was 20.90 (3.2) occurrences. No significant difference was noted between the behavior of encircle in control and males exposed to molinate (ANOVA, $\mathrm{df}=1, \mathrm{~F}=1.234, \mathrm{p}=0.281$ ). TailNose was defined as the male touching the female's side or tail with their nose or head. In control males mean was 24.20 (4.4) occurrences. In treatment males the mean was 22.80 (5.1) occurrences. No significant difference was noticed between the behavior of tail-nose in control and males exposed to molinate (ANOVA, df $=1, \mathrm{~F}=0.043, \mathrm{p}=0.839$ ). Follow was defined as the male swimming behind the female changing direction when she changes direction. In control males the mean was 49.00 (5.2) occurrences. In males exposed to molinate, the mean was 43.80 (7.1) occurrences and there was no significant difference between the behavior of follow in control and treatment males (ANOVA, $\mathrm{df}=$ $1, \mathrm{~F}=0.008, \mathrm{p}=0.929$ ).

Control males exhibited Possible Spawn with the mean at 5.40 (2.4) occurrences. In treatment males the mean was 7.80 (3.6) occurrences. There was no significant difference between the behavior of possible spawn in control and treatment males (ANOVA, $\mathrm{df}=1$, $\mathrm{F}=0.302, \mathrm{p}=0.589)$. Egg data revealed approximately twice as many fertile eggs produced by untreated mating pairs versus molinate-treated mating pairs (Fig. 1)

Findings indicate significant treatment differences in acetylcholinesterase activity in zebrafish exposed to molinate $(\mathrm{p}<0.05)$ compared to zebrafish controls (untreated) based on one way repeated measures ANOVA of AChE activity over a time period of $1 \mathrm{~min}$ to 15 min (Fig. 2). The AChE activities in molinatetreated males were significantly higher at every time point tested: $1,2,5,10$, and $15 \mathrm{~min}$.

\section{DISCUSSION}

Molinate is an herbicide that acts as a cholinesterase inhibitor. Animals exposed to cholinesterase inhibitors have shown signs of muscular twitching from excessive contraction of muscles, extreme weakness, and often paralysis because of this inhibition, (Hodgson and Levi 1987). Locomotion and equilibrium can be affected due to the accumulation of acetylcholine in fish exposed to carbamate insecticides, (Little et al. 1990; Richmonds and Dutta 1992; Saglio et al. 1996).

Previous studies by Sancho et al. (2000) and Fernandez-Vega et al. (1999) show physical changes in animals following exposure to carbamates. Specific 


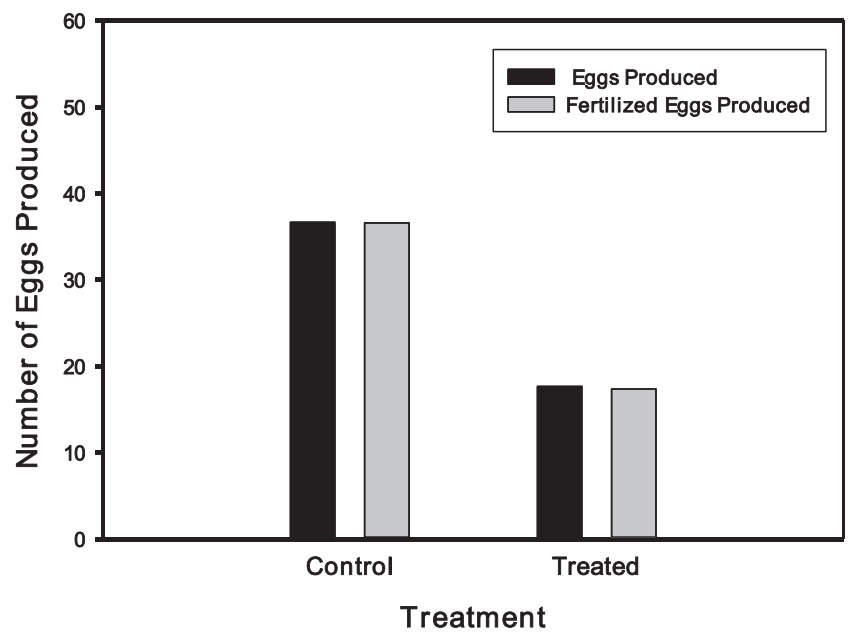

FIG. 1. Egg production following exposure to $15 \mathrm{mg} / \mathrm{L}$ of molinate or water (control) for two hours. Findings indicate significant differences in total eggs produced and total fertilized eggs produced in zebrafish exposed to molinate $(\mathrm{p}<0.05)$ compared to zebrafish controls (untreated) based on Kruskal-Wallis One Way ANOVA on Ranks and all pairwise multiple comparison procedures based on the Tukey Test.

changes were noted in the Sancho et al. (2000) study, such as lethargy and reduced opercular movements in eels exposed to molinate. European eels (Anguilla anguilla) were exposed to a pesticide concentration of $11.15 \mathrm{mg} / \mathrm{L}$ and sampled for cholinesterase at 6, 24, 48, 72, and $96 \mathrm{hrs}$ following exposure to the toxicant. Various behaviors were observed ranging from lethargy to erratic swimming and tremors in the study by Fernandez-Vega et al. (1999).

It may be deduced that zebrafish exposed to molinate may have similar effects based on the results in previous studies. The reproductive and spawning behavior of treated zebrafish did not seem to be affected under the conditions in this experiment and exposure time of $2 \mathrm{hrs}$ to $15 \mathrm{mg} / \mathrm{L}$ molinate. Significant differences in behaviors of encircle, tail-nose, follow, and possible spawn were not observed between control and treated animals. There are several possibilities that may explain why there were no significant differences observed between control and treated animals following molinate exposure. One explanation is that the treatment times might have been too short to cause an observable change in the behavior of the animal. The treatment times were determined based on pilot studies that showed maximum exposure time resulting in no mortalities. The behaviors that were scored following exposure may not have been affected by the exposure to molinate or the behavior changes were too subtle to observe on videotape on such a small fish. Also, there might have been changes in behaviors other than those scored in this particular experiment but such behaviors, if existed, were too subtle to score.

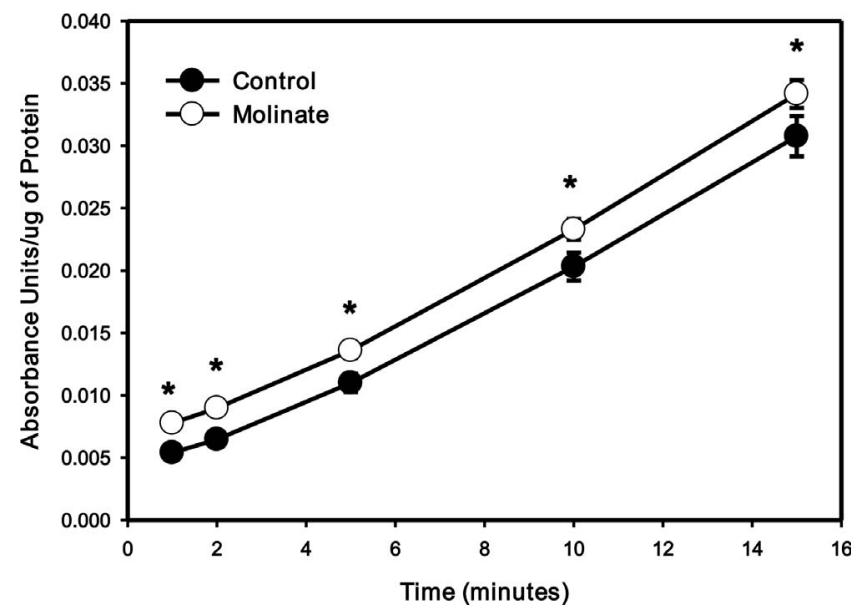

FIG. 2. Acetylcholinesterase Activity in heads of zebrafish exposed to $15 \mathrm{mg} / \mathrm{L}$ of molinate or water (control) for two hours. Findings indicate significant differences in acetylcholinesterase activity in zebrafish exposed to molinate $(\mathrm{p}<0.05)$ compared to zebrafish controls (untreated) based on one-way repeated measures ANOVA and the Holm-Sidak method for all pairwise multiple comparison procedures.

Our study revealed that untreated mating pairs produced significantly more eggs than treated mating pairs with no changes to spawning behavior. Because female zebrafish release hormones on ovulation that stimulate male reproductive behavior (Van Den Hurk et al. 1987), the molinate-treated males might have had a compromised nervous system, making them less responsive to the hormones released by the females. Future studies should examine olfactory rosettes of males following exposure to molinate. Damaged olfactory rosettes of males may lead to a decrease in successful spawning due to lack of hormone binding response by males leading to overall lower fertile egg production. The olfactory rosettes of males are critical for successful spawning (Fujita et al. 1991).

Zebrafish exposed to molinate at a dosage of $15 \mathrm{mg} / \mathrm{L}$ for a two-hour period exhibited significantly higher levels of acetylcholinesterase. Thiocarbamates such as molinate can inhibit acetylcholinesterase activity (PenaLlopis et al. 2001; USEPA 2000). Cholinesterase activity decreased significantly in European eel after exposure to sublethal concentrations of molinate in previous studies (Sancho et al. 1998; Sancho et al. 2000). However, results of this study demonstrate that the acetylcholinesterase activity in the head increased.Studies by Sancho et al. (2000) and Ceron et al. (1996) showed that the European eel exposed to molinate did not produce a high reduction in cholinesterase activity in the tissue compared to plasma and whole blood. The present study shows that acetylcholinesterase activity was only evaluated in the head. Decreased activity might have been present in whole blood or plasma samples or possibly muscle tissue if examined. 
The exposure time in this study was designated for two hours. The time between exposure and sample collection was 19-24 hrs. This may account for the increased levels of acetylcholinesterase observed in the brain tissue. The time period between exposure and collection might have been sufficient enough for the treated fish to recover from the exposure inducing a feedback response. The upregulation of acetylcholinesterase has been observed by others (Mor and Soreq 2011) demonstrating uncontrolled cholinergic hyperexcitation while inducing a feedback response of acetylcholinesterase overproduction following exposure to anticholinergic insecticides. Both carbamate and an herbicide propanil (also used for control of grassy and broad-lead weeds) increased transcription of several genes associated with protein biosynthesis. Propanil, in particular, induced genes coding for neuronal pathways (Pereira et al. 2010). Such transcriptional changes observed could possibly explain the recent reports of $\mathrm{AChE}$ activation following pesticide exposure in rice field conditions. Acetylcholinesterase activation initially was observed in brain of fish exposed to various herbicides such as penoxsulam, imazethapyr, and imazaspic. However, prolonged or chronic exposures of such herbicides reversed the activation and inhibited AChE activity (Cattaneo et al. 2010; Moraes et al. 2011).

\section{CONCLUSION}

Molinate does not appear to impact male courtship behavior in zebrafish based on the conditions of the present study. However, significant increases in AChE activity following molinate exposure suggest the possibility of disruption of the nervous system in males. The response of fish by significantly increasing $\mathrm{AChE}$ activity in treated males may be the cause of the fewer fertilized eggs produced by treated pairs compared to the untreated pairs.

Further exploration of egg laying and impact of the viability of eggs should be explored.

It is unclear whether molinate impacts behavior as a result of disrupting acetylcholinesterase activity in zebrafish under the exposure of two hours with a collection time of $19+$ hrs. Future experiments of collecting blood samples at the end of the two-hour exposure time and at the end of the experimental trials should clarify the results. There might have been a lowered level of acetylcholinesterase at the end of the exposure time, but the levels were not tested until the conclusion of the behavioral sequencing. Also, the experiment could have been designed to lessen the gap between the exposure time and the collection time. However, this might not have allowed the treated animals enough time to recover prior to the spawning sequence and might have been detrimental to the collection of the behavioral data. Furthermore, chronic exposure of molinate may inhibit AChE activity with concomitant alteration in reproductive behavior.

Acknowledgments: This project was supported by an HBCU Master's Degree STEM Program research minigrant funded by Title III at Fayetteville State University. Studies involving experimental animals were conducted in accordance with the national and institutional guidelines for the protection of animal welfare.

\section{LITERATURE CITED}

BLOOM, H. D., AND PERLMUTTER, A. 1977. A sexual aggregating pheromone system in the Zebrafish, Brachydanio rerio (Hamilton-Buchanan). Journal of Experimental Zoology. 199:215-226.

BRADFORD, M. M. 1976. A rapid and sensitive method for the quantitation of microgram quantities of protein utilizing the principle of protein-dye binding. Anal. Biochem. 72:248-254.

CATTANEO, R., CLASEN, B., LUCIA LORO, V., DE MENEZES, C. C., MORAES, B., SANTI, A., TONI, C., DE AVILA, L. A., AND ZANELLA, R. 2011. Toxicological responses of Cyprinus carpio exposed to the herbicide penoxsulam in rice field conditions. Journal of Applied Toxicology. 31(7):626-632.

CERON, J. J., FERRANDO, M. D., SANCHO, E., GUTIERREZPANIZO, C., AND ANDREU-MOLINER, E. 1996. Effects of diazinon exposure on cholinesterase activity in different tissues of European eel (Anguilla anguilla). Exotoxico. Environ. Saf. 35:222-225.

CHEN, L. C., AND MARTINICH, R. L. 1975. Pheromonal stimulation and metabolite inhibition of ovulation in the zebrafish, Brachydanio rerio. Fish. Bull., (Natl. Mar. Fish. Serv. U.S.). 73:889-894.

DARROW, K. O., AND HARRIS, W. A. 2004. Characterization and development of courtship in Zebrafish, Danio rerio. Zebrafish. 1(1):40-45.

DE GAUDEMAR, B., AND BEALL, E. 1999. Reproductive behavioral sequences of single pairs of Atlantic salmon in an experimental stream. Animal Behaviour. 57:1207-1217.

Ellman, G. L., COURTNEY, K. D., ANDRES, V. JR., AND FEATHER-STONE, R. M. 1961. A new and rapid colorimetric determination of acetylcholinesterase activity. Biochemical Pharmacology. 7:88-95.

FERNANDEZ-VEGA, C., SANCHO, E., FERRANDO, M. D., AND ANDREU, E. 1999. Thiobencarb toxicity and plasma AChE inhibition in the European eel. Journal of Environmental Science and Health Part B. 34(1):61-73.

FRASCO, M. F., FOURNIER, D., CARVALHO, F., AND GUILHERMINO, L. 2006. Cholinesterase from the common prawn (Palaemon serratus) eyes: catalytic properties and sensitivity to organophosphate and carbamate compounds. Aquatic Toxicology. 77:412-421.

FUJITA, I., SORENSON, P. W., STACEY, N. E., AND HARA, T. J. 1991. The olfactory system, not the terminal nerve, functions as the primary chemosensory pathway mediating responses to sex pheromones in male goldfish. Brain Behavior and Evolution. 38:313-321.

GALHANO, V., PEIXOTO, F., GOMES-LARANJO, J., AND FERNANDEZ-VALIENTE, E. 2009. Comparative toxicity of bentazon and molinate on growth, photosynthetic pigments, photosynthesis, and respiration of the Portuguese ricefield cyanobacterium Nostoc muscorum. Environmental Toxicology. 25(2):147-156 
GRUE, C. E., GIBERT, P. L., And SEELEY, M. E. 1997. Neurophysiological and behavioral changes in non-target wildlife exposed to organophosphate and carbamate pesticides: thermoregulation, food consumption and reproduction. American Zoology. 37:369-388.

GUILlETTE, L. J. JR., ARNOLD, S. F., AND McLACHLAN, J. A. 1996. Ecoestrogens and embryos - is there a scientific basis for concern? Animal Reproductive Science. 42(1-4):13-24.

GUPTA, R. C. 1994. Carbofuran toxicity. Journal of Toxicology and Health. 43:383-418.

GUTHRIE, D. M., AND MUNTZ, W. R. A. 1993. Role of vision in fish behavior. In: Behaviour of TeleostFishes. T. J. Pitcher (ed.), Chapman and Hall, London pp. 89-121.

HODGSON, E., AND LEVI, P. E. 1987. A Textbook of Modern Toxicology. Elsevier Science Publishers, New York, USA. 139-140 pp.

JASH, N. B., AND BHATTACHARYA, S. 1983. Delayed toxicity of carbofuran in freshwater teleosts, Channa punstatus (BLOCH) and Anabas testudineus (BLOCH). Water, Air, and Soil Pollution. 19(3):209-213.

JULLI, M., AND KRASSOI, F. R. 1995. Acute and chronic toxicity of the thiocarbamate herbicide, molinate, to the cladoceran Moina australiensis Sars. Bulletin of Environmental Contamination and Toxicology. 54(5):690-694.

LITTle, E. E., ARCHESKI, R. D., FLEROV, B. A., AND KOZLOVSKAYA, V. I. 1990. Behavioral indicators of sublethal toxicity in Rainbow Trout. Archives of Environmental Contamination and Toxicology. 19:380-385.

MARTIN, P., AND BATESON, P. 1993. Measuring Behaviour: An Introductory Guide. Cambridge University Press, Cambridge. $187 \mathrm{p}$.

MOR, I., AND SOREQ, H. 2011. Chapter 66-Cholinergic toxicity and the male reproductive system. Reproductive and Developmental Toxicology. 863-870.

MORAES, B. S., CLASEN, B., LORO, V. L., PRETTO, A., TONI, C., ANTONIO DE AVILA, L., MARCHESAN, E., LUIZ DE OLIVEIRA MACHADO, S., ZANELLA, R., AND REIMCHE, G. B. 2011. Toxicological responses of Cyprinus carpio after exposure to a commercial herbicide containing imazethapyr and imazapic. Ecotoxicology and Environmental Safety. 74:328-335.

OLIVEIRA, R. F., ROS, A. F. H., AND GONCALVES, D. M. 2005. Intra-sexual variation in male reproduction in teleost fish: a comparative approach. Hormones and Behavior. 48:430-439.

PENA-LLOPIS, S., PENA, J. B., SANCHO, E., FERNANDEZVEGA, C., AND FERRANDO, M. D. 2001. Glutathionedependent resistance of the European eel Anguilla anguilla to the herbicide molinate. Chemosphere. 45:671-681.

PEREIRA, J. L., HILL, C. J., SIBLY, R. M., BOLSHAKOV, V. N., GONÇALVES, F., HECKMANN, L. H., AND CALLAGHAN, A. 2010. Gene transcription in Daphnia magna: effects of acute exposure to a carbamate insecticide and an acetanilide herbicide. Aquat. Toxicol. 97(3):268-276.

QUIGNOT, N., ARNAUDA, M., ROBIDEL, F., LECOMTEA, A., TOURNIER, M., CREN-OLIVÉ, C., BAROUKI, R., AND LEMAZURIER, E. 2012. Characterization of endocrinedisrupting chemicals based on hormonal balance disruption in male and female adult rats. Reproductive Toxicology. 33:339-352.

RICHMONDS, C., AND DUTTA, H. M. 1992. Effect of malathion on the optomotor behavior of bluegill sunfish, Lepomis macrochirus. Comparative Biochemical Physiology. 102:523-526.

ROWLAND, W. J., GRINDLE, N., MACLAREN, R. D., AND GRANQUIST, R. 2002. Male preferences for a subtle posture cue that signals spawning readiness in female sticklebacks. Animal Behaviour. 63:743-748.

SAGLIO, P., TRIJASSE, S., AND AZAM, D. 1996. Behavioral effects of waterborne carbofuran in goldfish. Archives of Environmental Contamination and Toxicology. 31:232-238.

SALEK, S. J., GODWIN, J. R., STACEY, N. E., AND SULLIVAN, C. V. 2001a. Courtship and tank spawning behavior of temperate basses (genus Morone). Transactions of the American Fisheries Society. 130:833-847.

SALEK, S. J., SUlliVAN, C. V. S., AND GODWIN, J. R. $2001 \mathrm{~b}$. Courtship behavior of male white perch, Morone americana: evidence for control by androgens. Comparative Biochemistry and Physiology. Part A, Molecular \& integrative physiology 130(4):731-740.

SANCHEZ, M., ANDREU-MOLINER, E., AND FERRANDO, M. D. 2004. Laboratory investigation into the development of resistance of Daphnia magna to the herbicide molinate. Ecotoxicology and Environmental Safety. 59:316-323.

SANCHO, E., CERON, J. J., AND FERRANDO, M. D. 2000. Cholinesterase activity and hematological parameters as biomarkers of sublethal molinate exposure in Anguilla anguilla. Ecotoxicology and Environmental Safety. 46:81-86.

SANCHO, E., FERRANDO, M. D., AND ANDREA, E. 1998. In vivo inhibition of AChE activity in the European eel $A$ anguilla exposed to technical grade fenitrothion. Comp. Biochem. Physiol. C 120:389-395.

SPENCE, R., AND SMITH, C. 2005. Male territoriality mediates density and sex ratio effects on oviposition in the zebrafish, Danio rerio. Animal Behaviour, Volume 69(6):1317-1323.

TROTTER, D. M., KENT, R. A., AND WONG, M. P. 1991. Aquatic fate and effects of carbofuran. Critical Reviews in Environmental Control. 21(2):137-176.

U.S. ENVIRONMENTAL PROTECTION AGENCY. 2000. Thiocarbamates: a determination on the existence of a common mechanism of toxicity and a screening level cumulative food risk assessment (Attachment 1). U.S. EPA Office of Pesticide Programs, Health Effects Division, December 1, 2000.

U.S. NATIONAL LIBRARY OF MEDICINE. 1995. Hazardous Substances Data Bank. Bethesda, MD. 4-5 pp.

VAN DEN HURK, R., AND LAMBERT, J. G. D. 1983. Ovarian steroid glucuronides function as sex pheromones for male zebrafish, Brachydanio rerio. Can. J. Zool. 61:2381-2387.

VAN DEN HURK, R., SCHOONEN, W. G. E. J., VAN ZOELEN, G. A. AND LAMBERT, J. G. D. 1987. The biosynthesis of steroid glucuronides in the testis of the Zebrafish, Brachydanio rerio, and their pheromonal function as ovulation inducers. General and Comparative Endocrinology 68:179-188.

WESTERFIELD, M. 1989. The Zebrafish Book: A Guide for the Laboratory Use of Zebrafish (Brachydanio rerio). University of Oregon Press, Eugene, OR. 